Provided for non-commercial research and education use. Not for reproduction, distribution or commercial use.

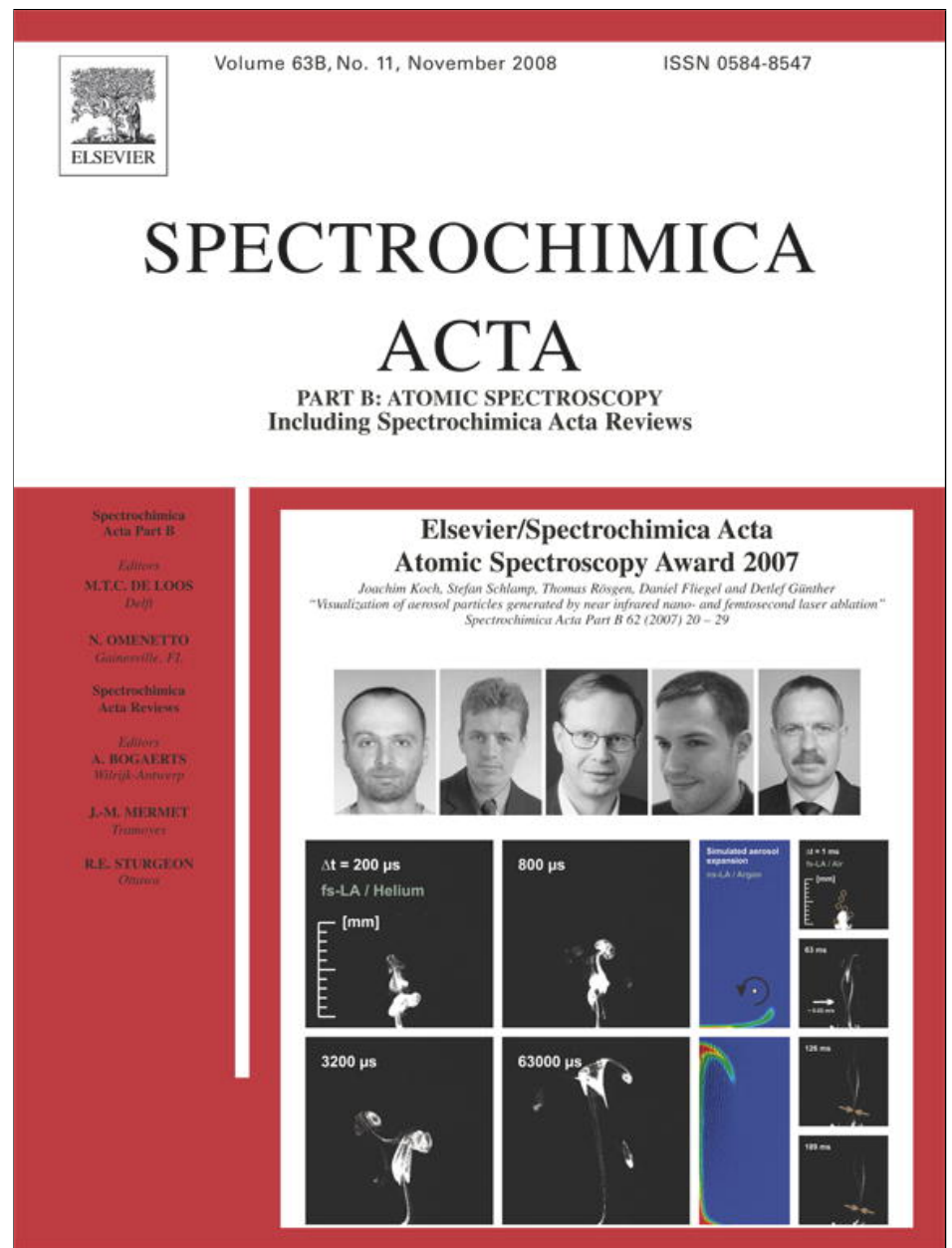

This article appeared in a journal published by Elsevier. The attached copy is furnished to the author for internal non-commercial research and education use, including for instruction at the authors institution and sharing with colleagues.

Other uses, including reproduction and distribution, or selling or licensing copies, or posting to personal, institutional or third party websites are prohibited.

In most cases authors are permitted to post their version of the article (e.g. in Word or Tex form) to their personal website or institutional repository. Authors requiring further information regarding Elsevier's archiving and manuscript policies are encouraged to visit:

http://www.elsevier.com/copyright 


\title{
Characterization of green copper phase pigments in Egyptian artifacts with X-ray absorption spectroscopy and principal components analysis
}

\author{
Deborah Lau $^{\text {a,* }}$, Peter Kappen ${ }^{\text {b }}$, Marika Strohschnieder ${ }^{\mathrm{c}}$, Narelle Brack ${ }^{\mathrm{b}}$, Paul J. Pigram ${ }^{\mathrm{b}}$ \\ a CSIRO Division of Materials Science and Technology, Private Bag 33, Gate 5 Normanby Rd, Clayton, Victoria 3168, Australia \\ b Centre for Materials and Surface Science and Department of Physics, La Trobe University, Victoria 3086, Australia

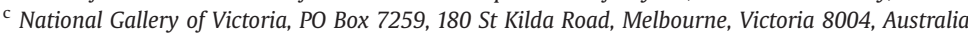

\section{A R T I C L E I N F O}

\section{Article history:}

Received 26 October 2007

Accepted 18 September 2008

Available online 4 October 2008

\section{Keywords:}

Egyptian pigments

Exploratory analysis

PCA

XANES

\begin{abstract}
A B S T R A C T
The characterization of materials in historical artifacts can contribute significantly to their preservation and understanding; however, sampling and characterization are ideally performed using non-destructive approaches. The analysis of green pigments from Egyptian artifacts presents a further challenge as responses to laboratory based techniques have proven unsuccessful in many cases. An alternative approach is the use of non-destructive X-ray absorption near-edge structure spectroscopy, which was performed on a reference set of copper-containing green minerals and other compounds. Data projection using principal component analysis was used to explore the spectral data structures and to illustrate the relationship between the spectra and copper speciation, resulting in a calibration or training set of the reference materials used. Data from the training set were compared with samples from Egyptian artifacts. The combination of X-ray absorption spectroscopy with principal components analysis provides a novel approach in archeometry and the characterization of objects of cultural heritage.

Crown Copyright @ 2008 Published by Elsevier B.V. All rights reserved.
\end{abstract}

\section{Introduction}

The conservation of culturally significant artifacts is greatly assisted by the scientific analysis and identification of materials used in their construction. The knowledge of the material composition of an artwork may be used to inform decisions relating to treatment, storage and display as well as aid in provenancing, attribution and authentication. The identification of specific pigments used for coloration is a key piece of information that is often employed for authentication. Manufactured pigments only become available after their invention and acceptance as a colorant, and, due to trends in artistic preferences, have a tendency to be used within specific windows of time. An approach such as this is only possible when we have pre-existing knowledge of which pigments were used during particular historical periods, which in turn is reliant on the collective documentation of a number of occurrences.

A primary constraint controlling the analysis of valuable artworks is the need to use non-destructive or micro-destructive analytical methods. Ideally, the impact on the object should be minimized; the preferred approach avoids sampling altogether. If this is not possible then sampling should be limited to the smallest amount that can produce a useful result, generally of the order of micrograms to picograms, and analysis should proceed using a non-destructive nonconsumptive approach leaving the sample available for further

\footnotetext{
* Corresponding author.

E-mail address: Deborah.Lau@csiro.au (D. Lau).
}

examination with other techniques [1]. In a review of non-destructive analysis and testing of museum objects [2], Adriaens reiterates an important conservation principle, that we should aim for the maximization of information with a minimization of consumed volume of sample.

In the case of Egyptian artifacts, there is less published information available on the successful identification of green than any other color [3-5], a finding which has been reinforced during our examination of green pigments in Egyptian artifacts from the National Gallery of Victoria (Melbourne, Australia). In preliminary investigations of the Coffin of Tjseb (the coffin is described in detail later in this section), using laboratory-based non-destructive techniques of micro-Raman spectroscopy and micro-X-ray diffraction (micro-XRD), we were unable to collect Raman spectra due to inherent sample fluorescence, and micro-XRD was hampered by an extremely low signal, even with extended collection times. Complementing laboratory-based surface and structure analytical techniques, synchrotron X-ray absorption near-edge structure (XANES) spectroscopy has proven a valuable tool to investigate oxidation states and chemical speciation [6-8]. XANES is element sensitive and directly probes the atomic near-range order and symmetry around an element of interest in a given material, for example, $\mathrm{Cu}$ in green Egyptian pigments.

Multivariate analysis is rapidly gaining popularity as a tool for the interpretation of spectral data, and principal components analysis (PCA) is one of the most used techniques for discerning structural relationships between samples based on the projection of data [9-12]. PCA reduces the dimensionality in a data set while retaining the 
information contained within the data. Using a linear transformation, the original data set containing $N$ samples and $I$ variables, and thus containing $I$-dimensions of variability, is transformed to a visually recognizable form represented in far fewer (usually 2 or 3 ) dimensions. The new transformed matrix contains a data set representing the variance and co-variance within the data, where the greatest variance lies on the projection of the first coordinate, the first principal component, down to the $N$ th principal component.

PCA is an ideal approach for the direct examination of XANES spectra where subtle spectral differences are sometimes difficult to discern visually or with conventional data modeling techniques. Minimal XANES data handling (background subtraction and normalization) is required for PCA. Further data treatment such as the extraction of the XAS oscillations $(\chi(k))$ and subsequent Fourier analysis is not necessary. PCA provides a valuable and objective method for comparison of numerous XANES spectra. PCA scores plots allow exploration of sample co-variance in a reciprocal data space, providing an opportunity to define sample groupings, examine sample groupings and establish relationships within the identified groups. In the case of historic copper containing pigments, the relationships between $\mathrm{Cu}$ K-edge XANES spectra may be used to obtain chemical speciation and/or structural information for the pigments via PCA classification of XANES spectra according to the properties of the materials investigated. This method has been used here to assess unknown $\mathrm{Cu}$ containing green pigments used in ancient Egyptian artifacts in the collection of the National Gallery of Victoria, Australia.

A relatively simple color palette of pigments was used in Egyptian tombs and relics. White pigments include calcium sulfates (gypsum, $\mathrm{CaSO}_{4} \cdot 2\left(\mathrm{H}_{2} \mathrm{O}\right)$ and anhydrite, $\left.\mathrm{CaSO}_{4}\right)$, huntite $\left(\mathrm{Mg}_{3} \mathrm{Ca}\left(\mathrm{CO}_{3}\right)_{4}\right)$, and calcium carbonate (chalk or calcite, $\mathrm{CaCO}_{3}$ ). Carbon black of various forms was used, and red and yellow pigments were typically red (hematite, $\mathrm{Fe}_{2} \mathrm{O}_{3}$ ) or yellow ochre (goethite, $(\mathrm{FeO}(\mathrm{OH}))$. On occasion, orpiment $\left(\mathrm{As}_{2} \mathrm{~S}_{3}\right)$ or realgar $\left(\mathrm{As}_{4} \mathrm{~S}_{4}\right)$ has been identified in royal tombs $[3,4]$.

Blue and green Egyptian pigments are typically $\mathrm{Cu}$ containing phases, with the coloration arising from d-shell electronic transitions. Egyptian blue is the first known artificially synthesized pigment. It was developed during the Old Kingdom (2600 BC) and used until the Roman period [13]. It is a synthetic copper silicate, with the chemistry of the naturally occurring mineral cuprorivaite, $\mathrm{CaCuSi}_{4} \mathrm{O}_{10}$, prepared by firing a mixture of compounds containing silicon (silica as sand), calcium (chalk or lime), a source of copper (copper minerals or bronze filings) and a soda flux [14]. This produces a heterogeneous product comprised predominantly of manufactured blue cuprorivaite. Modification of mixing ratios directly influences the composition of the end product. A high silica ratio in the mixture leads to increased $\mathrm{SiO}_{2}$ phases (e.g.; quartz, cristobalite, and tridymite), additional chalk or lime increases the amount of wollastonite $\left(\mathrm{CaSiO}_{3}\right)$, and an increase in the formation of copper oxides such as cuprite and tenorite is due to $\mathrm{Cu}$ added in excess [15]. The strong blue coloration of cuprorivaite is attributed to $\mathrm{Cu}^{2+}$ within a square planar arrangement [16].

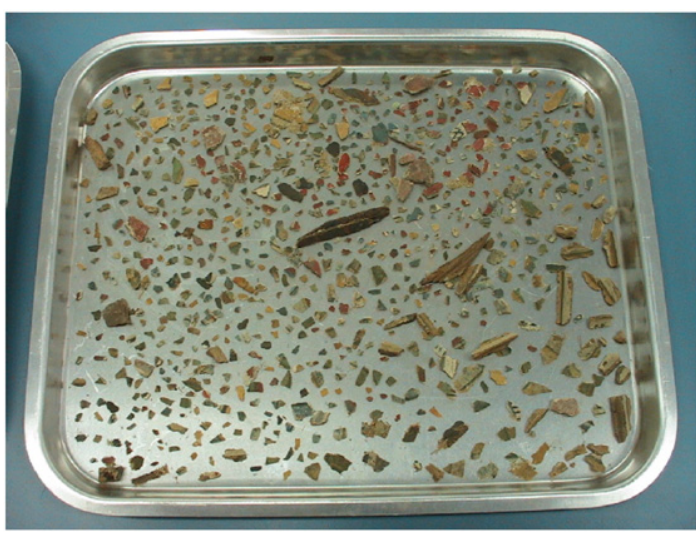

Fig. 2. Dislocated paint fragments stored on trays.

It has been reported that naturally produced malachite was used as a green pigment only rarely [17] and most greens are Egyptian green which was produced in the same manner as Egyptian blue from the beginning of the Eighteenth Dynasty [18] but with higher lime, lower copper content and higher firing temperature $[14,19,20]$. Again, the process produces a heterogeneous product but with the main crystalline constituents being wollastonite and parawollastonite, two isomorphs of $\mathrm{CaSiO}_{3}$, in which the $\mathrm{Cu}^{2+}$ chromophore is located in a distorted octahedral site in an amorphous (glassy) phase [16]. It was originally thought that Egyptian green may have been produced as a mis-fired or weathered Egyptian blue, but it is now believed that it was deliberately produced as a distinct green color [21].

Alongside the occurrence of synthetic Egyptian green and naturally occurring malachite in Egyptian funerary objects, green coloration has been reported as the result of degradation of Egyptian blue by either of two mechanisms. In the first, the original blue color may change to a faint green as copper ions are leached out of Egyptian blue and combine with chloride ions and calcium carbonate forming the basic copper chlorides atacamite and paratacamite [22]. The second mechanism describes instances where the organic binding medium around Egyptian blue pigment particles has darkened or yellowed significantly, altering the appearance of what was originally intended blue, to a green color [23].

The first coffin examined in this study (Coffin I), accession number D146-1982, dates to the Third Intermediate to Late period, 25th Dynasty-early 26th Dynasty (747-600 BC). The coffin is constructed from wooden formwork and covered with mud, then coated with fabric and a white ground layer supporting the colored paint layer used to decorate the coffin lid. It is heavily fragmented and several larger pieces exist (Fig. 1) along with a large number of smaller 1$5 \mathrm{~mm}$ dislocated flakes which may be mixed with paint flakes from one or more other objects, stored in several trays (Fig. 2). Since no

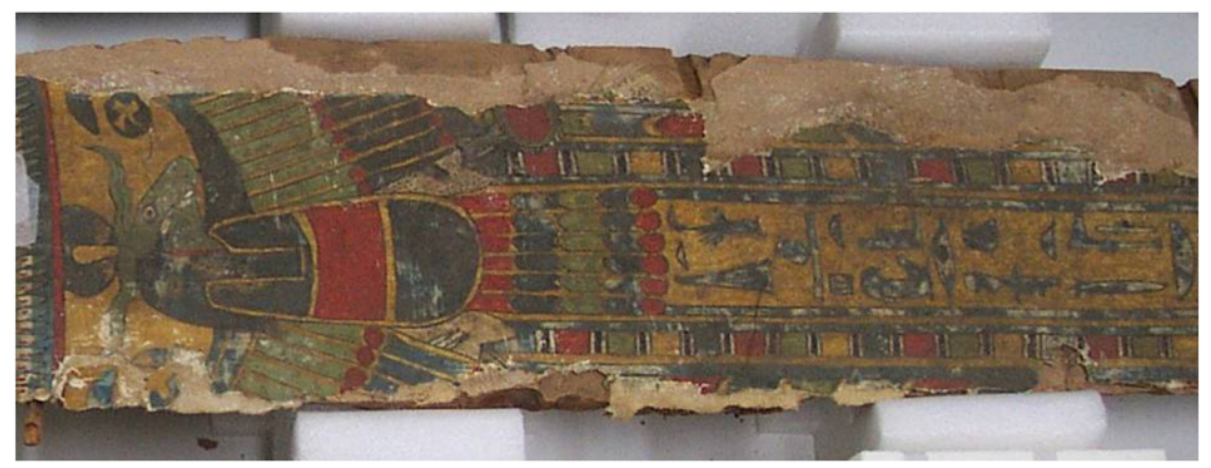

Fig. 1. Fragment of the lid from the inner anthropoid coffin of Tjeseb. 
previous conservation treatments have been performed, there is no gross contamination of the original materials with consolidants, inpainting or adhesives. As a consequence, the artifact provides an important opportunity to study and document the materials and processes used in ancient Egypt through examination of the coffin. The second coffin (Coffin II), accession number D234-1994, is a heavily decorated, large wooden fragment of a mummy board dating from 715-332 BC, the late period, 25th-30th Dynasty. Little historical information accompanies this object.

For the work reported here XANES (X-ray absorption near edge spectroscopy) was used to characterize copper-containing blue and green reference samples. These reference materials were sourced from minerals known to have been used as pigments or have the composition of their degradation products. Artificially aged Egyptian blue (which exhibited a green color) was prepared and included for comparison. PCA was then utilized to explore structural relationships within and between groups of copper phases and define phase structures relating to crystal chemistry, occurring as identifiable groups in the dataset. The combination of XANES with PCA was then used to suggest the identity of green pigments found on the aforementioned Egyptian painted artifacts. This combined approach to the characterization of samples of cultural heritage value has, to the best of our knowledge, not been reported previously. This study aims to demonstrate the value of XANES-PCA as a tool for archeometry and object conservation.

\section{Experimental}

\subsection{Reference samples and sample preparation}

For transmission XANES analyses, mineral reference samples were provided by the Museum of Victoria (Melbourne, Australia) with a verified mineralogical composition and laboratory reagent grade copper compounds were used (Table 1). Egyptian green was not available from any collection or commercial source and could not be manufactured reliably. It was therefore not included in the minerals reference set. Egyptian blue pigment was obtained from Kremer Pigmente (Germany). Aged Egyptian blue was prepared by mixing an equal volume of Egyptian blue pigment powder with concentrated hydrochloric acid.

Table 1

Copper minerals and compounds examined with XANES

\begin{tabular}{lll}
\hline No & Sample & Chemical formula \\
\hline 1 & Cuprite 1 & $\mathrm{Cu}_{2} \mathrm{O}$ \\
2 & Cuprite 2 & $\mathrm{Cu}_{2} \mathrm{O}$ \\
3 & Tenorite & $\mathrm{CuO}$ \\
4 & Atacamite 1 & $\mathrm{Cu}_{2}(\mathrm{OH})_{3} \mathrm{Cl}$ \\
5 & Atacamite 2 & $\mathrm{Cu}_{2}(\mathrm{OH})_{3} \mathrm{Cl}$ \\
6 & Paratacamite & $\mathrm{Cu}_{2}(\mathrm{OH})_{3} \mathrm{Cl}$ \\
7 & Botallackite & $\mathrm{Cu}_{2} \mathrm{Cl}_{(}(\mathrm{OH})_{3}$ \\
8 & Azurite & $2 \mathrm{CuCO}_{3} \mathrm{Cu}(\mathrm{OH})_{2}$ \\
9 & Malachite & $\mathrm{CuCO}_{3} \mathrm{Cu}(\mathrm{OH})_{2}$ \\
10 & Dioptase & $\mathrm{CuSiO}_{2}(\mathrm{OH})_{2}$ \\
11 & Shattuckite & $\mathrm{Cu}_{5}\left(\mathrm{SiO}_{3}\right)_{4}(\mathrm{OH})_{2}$ \\
12 & Plancheite & $\mathrm{Cu}_{8} \mathrm{Si}_{8} \mathrm{O}_{22}(\mathrm{OH})_{4} \cdot\left(\mathrm{H}_{2} \mathrm{O}\right)$ \\
13 & Chrysocolla & $\left(\mathrm{Cu}_{1} \mathrm{Al}\right)_{2} \mathrm{H}_{2} \mathrm{Si} 2 \mathrm{O}_{5}(\mathrm{OH})_{4} \cdot \mathrm{n}\left(\mathrm{H}_{2} \mathrm{O}\right)$ \\
14 & Copper (II) chloride & $\mathrm{CuCl}_{2}$ \\
15 & Copper carbonate 1 & $\mathrm{CuCO}_{3}$ \\
16 & Copper carbonate 2 & $\mathrm{CuCO}_{3}$ \\
17 & Copper hydroxide & $\mathrm{CuOH}_{2}$ \\
18 & Copper sulphate & $\mathrm{CuSO}_{4}$ \\
19 & artificially aged Egyptian blue & \\
20 & Coffin I fragment & \\
21 & Coffin II fragment & \\
22 & Tray fragment (9) & \\
23 & Tray fragment (10) & \\
24 & Tray fragment (22) & \\
\hline
\end{tabular}

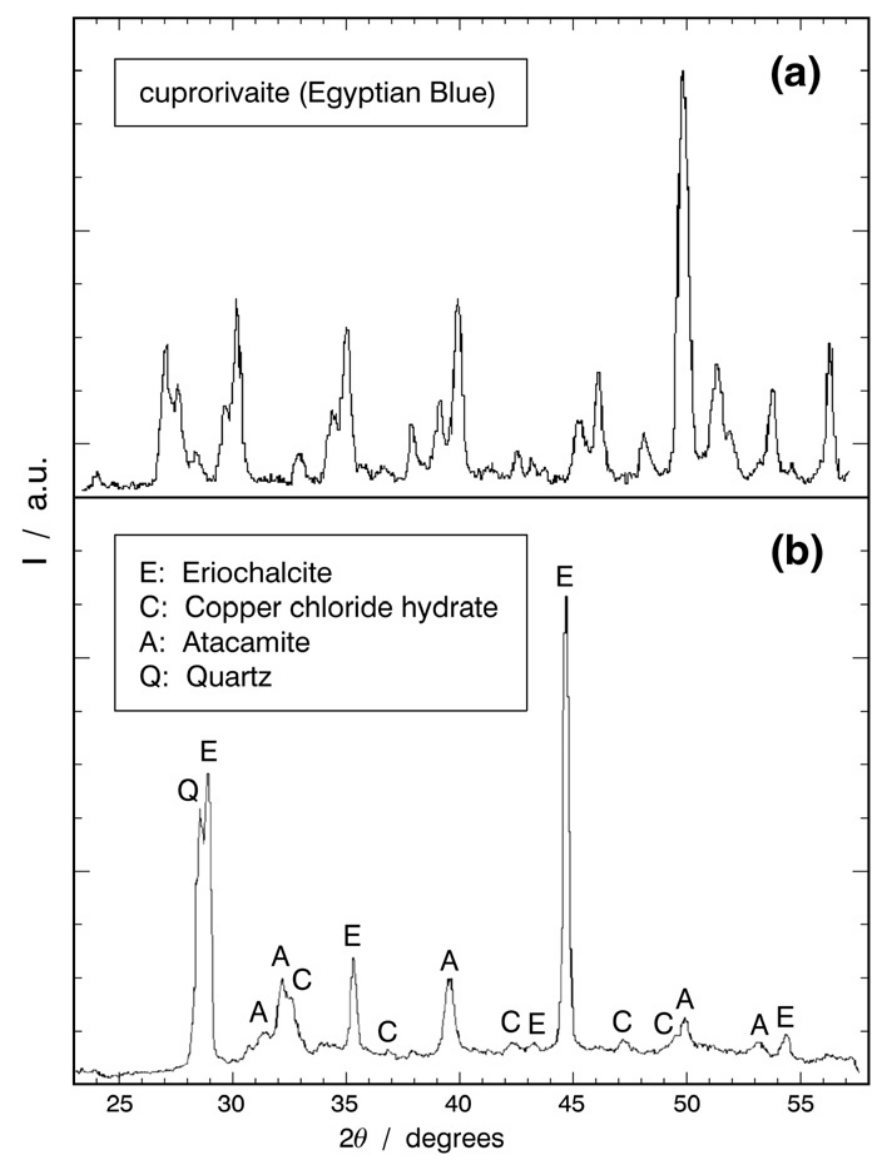

Fig. 3. XRD patterns from (a) Egyptian blue pigment and (b) laboratory aged Egyptian blue pigment. The abscissas in (a) and (b) are identical.

These materials were ground to fine powders in an agate mortar, carefully mixed with cellulose powder (Sigma-Aldrich, $30 \mu \mathrm{m}$ particle size) and pressed into $13 \mathrm{~mm}$ discs using a standard hydraulic die press (pressure $\sim 0.8 \mathrm{GN} / \mathrm{m}^{2}$ for $60 \mathrm{~s}$ ). The copper concentrations in these pellets depended on the availability of the respective reference materials. Care was taken to prepare sufficiently X-ray transparent samples (that is, absorption step $\Delta \mu \mathrm{d}<1.5$ ).

\subsection{Egyptian artifact samples}

Coffin fragments did not require any sample preparation and were used as received for fluorescence XANES. Samples are listed in Table 1 and were from:

- Coffin I

- The tray associated with Coffin I and

- Coffin II.

\subsection{XRD of Egyptian blue and aged Egyptian blue}

The composition of purchased Egyptian blue pigment and artificially aged Egyptian blue was verified with X-ray diffraction (XRD) (see Fig. 3). XRD was performed using a Bruker general area detection diffraction system (GADDS) microdiffractometer (Bruker AXS Inc., Madison, WI, USA) equipped with a HiStar gas-filled area detector and a vertical XYZ sample stage. Diffraction data were recorded with $\mathrm{Cu} \mathrm{K} \alpha$ radiation tube operating at $40 \mathrm{kV}$ and $40 \mathrm{~mA}$, monochromatized to wavelength 1.54056 A with a polycrystalline graphite incident monochromator. The incident beam was collimated to $300 \mu \mathrm{m}$ and collection times of $180 \mathrm{~s}$ were used. Recorded 2dimensional intensity patterns across the area detector were 
converted to conventional X-ray diffraction patterns by integration around the chi-circle with Bruker proprietary software. Phases were identified with the JCPDS-ICDD Powder Diffraction database (International Centre for Diffraction Data, PA, USA) and Bruker EVA (Version 4) software.

\subsection{XANES instrumentation and measurements}

Experiments were conducted at the Hamburg Synchrotron Radiation Laboratory (HASYLAB) at Deutsches Elektronen Synchrotron (DESY) in Hamburg, Germany. Cu-K edge XANES scans were recorded at the bending magnet beamlines $\mathrm{A} 1$ and $\mathrm{C}$. At both beamlines $\mathrm{Si}(111)$ double crystal monochromators were used (beamline A1: channel cut crystals). In each case, the monochromator energy resolution was approximately $\Delta E=1 \mathrm{eV}$, and the intensity of the monochromatic beam was monitored and controlled using an ionization chamber (filled with 1000 mbar $_{2}$ ) and a digital monochromator stabiliser (D-MoStab). Higher harmonics were suppressed by detuning the monochromator to $50 \%$ of the peak intensity. The beam size was controlled by a standard slit installed at the beamline $\left(8.0 \times 0.6 \mathrm{~mm}^{2}\right)$.

XANES scans of the reference samples were recorded in transmission mode using a second ionization chamber (filled with 1000 mbar Ar); scans of coffin fragments were acquired in fluorescence mode using a seven-element $\mathrm{Si}(\mathrm{Li})$ solid state detector (custom made Gresham Sirius). The data acquisition time was $\Delta t=1 \mathrm{~s}$ per data-point with energy step-widths $\delta E=0.2 \mathrm{eV}$ in the region around the absorption edge $(8970-9040 \mathrm{eV})$ and $\delta E=0.4 \mathrm{eV}$ above this region. Typical fluorescence total count rates were of the order of $20 \mathrm{kcps}$. The detector signals were pre-amplified within the experimental hutch. Further signal processing (outside the hutch) included seven digital signal processors (Canberra DSP 2060) feeding individual MCA cards that were linked to the beamline computer via a VME crate. For the fluorescence XANES scans, only $\mathrm{Cu}-\mathrm{K}_{\alpha}$ fluorescence signals were selected (via software), thus resulting in least background and optimized signal-to-noise ratios in the XANES spectra. For energy calibration purposes, XANES scans of a $\mathrm{Cu}$ foil were recorded, either simultaneously to or after acquisition of the data of interest. The absorption edge of the $\mathrm{Cu}$ foil was calibrated to $8979 \mathrm{eV}$. On selected samples repeat scans were acquired verifying the reproducibility of the results within the noise levels, which were typically found to be $\delta<2 \times 10^{-3}$ (transmission) and $\delta<10^{-2}$ (fluorescence) per scan. In the case of fluorescence spectra, up to six scans were added to improve the statistical quality of the data.

\subsection{Spectral processing}

XANES spectra were background subtracted and normalized to a post-absorption edge average of $\mu \mathrm{d}=1$ using the freeware XANDA Dactyloscope [24]. In order to reliably compare fluorescence and transmission mode XANES scans, the fluorescence data were corrected for self-absorption effects using the FLUO algorithm in ATHENA [25,26]. The stoichiometry of the pigments was estimated to contain copper-silicate-chlorides in a carbonate matrix. The strength of self-absorption correction was controlled through variation of the stoichiometry (relative carbonate content) and estimated from a comparison of transmission and fluorescence data acquired at the same time on one of the painted fragments.

For PCA analyses, the energy grids of the XANES scans were resampled (up-binned) to a constant step width of $\triangle E=0.3 \mathrm{eV}$. Only the region from $E>9007 \mathrm{eV}$ was used for PCA thus excluding the absorption edge and the first prominent maximum above the edge (white line). This step was taken since it was found that PCA results could be dominated by differences in the shape of the absorption edge and the prominence of the white line hence overruling any structural information contained in the XAS structures above the edge. In addition, potential mis-calibrations of the energy grid would have resulted in relative shifts of the absorption edges of the spectra affected, resulting in an introduction of artifacts into the PCA process. Furthermore, any uncertainties in the self-absorption correction process have the greatest impact on the most intense signals in XAS,
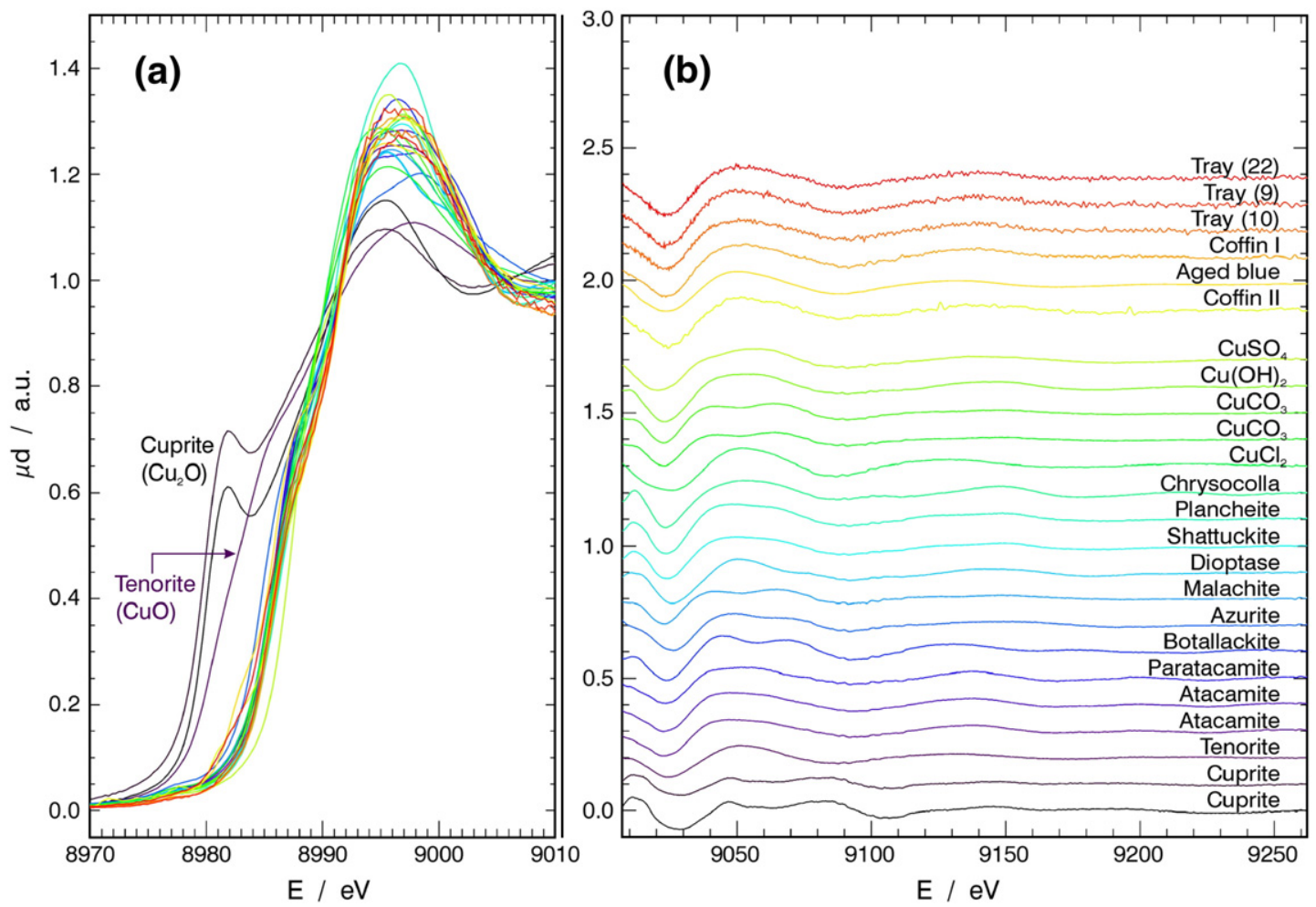

Fig. 4. (a) Overlaid plots of the edge region of all Cu XANES spectra (the marked spectra of cuprite and tenorite are distinctly different from the other spectra); (b) stacked plot of the post-edge region of all spectra (note that the offset in the vertical direction is arbitrary and does not represent any sample quality). 


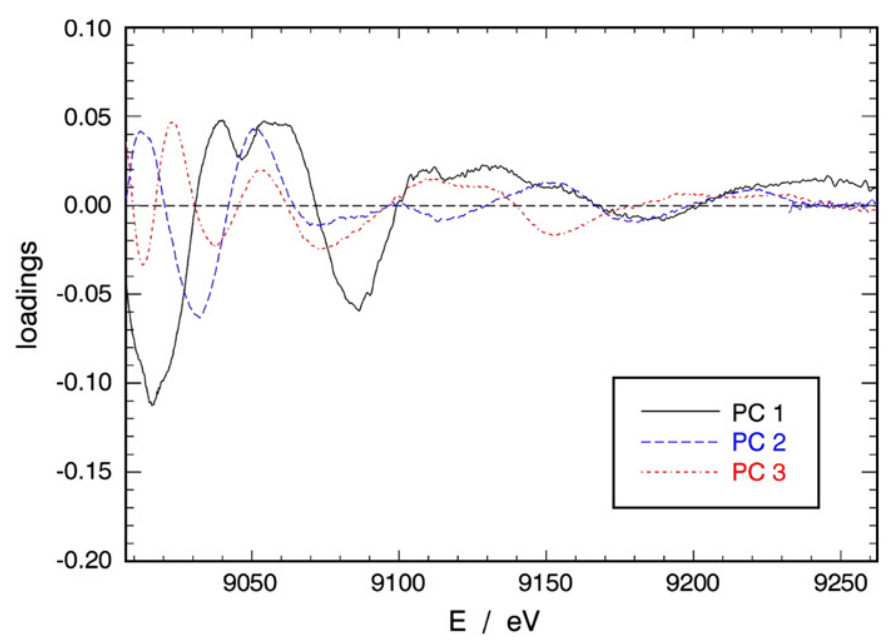

Fig. 5. Loadings plots for $\mathrm{PC} 1, \mathrm{PC} 2$ and $\mathrm{PC} 3$ of $\mathrm{Cu}$ minerals and laboratory $\mathrm{Cu}$ compounds.

that is, usually the white line. Excluding these sources of uncertainty increased the reliability of the PCA process.

After culling, the corresponding spectra (with $l=851$ data points each) were assembled in a matrix for PCA analyses. PCA was performed independently using standard routines in IDL [27] as well as the Unscrambler v 9.6 software package, CAMO, Norway, employing a random cross-validation approach. Both approaches involved removing the means in both dimensions of the input matrix of $N$ spectra (variables) and $l$ data points (observations). Both routines gave fully consistent results.

\section{Results and discussion}

\subsection{Assessment of known mineral and laboratory chemical spectra}

XANES data at the $\mathrm{Cu}$ K-edge of all minerals and laboratory chemicals are presented in Fig. 4. All spectra were background subtracted and normalized to a standard edge jump as described above. The left hand panel (a) shows details of the spectra around the absorption edge ( $8970 \mathrm{eV}-9010 \mathrm{eV}$ ), and in panel (b) only the postedge region for $E>9007 \mathrm{eV}$ is shown in a stacked plot.

Most distinct in Fig. $4 \mathrm{a}$ are the spectra of cuprite $\left(\mathrm{Cu}_{2} \mathrm{O}\right)$ with a shoulder in the absorption edge (around $8982 \mathrm{eV}$ ). Cuprite is the only mineral in the group that contains $\mathrm{Cu}$ in a single valence state $(+\mathrm{I})$, and because XANES is sensitive to the oxidation state of a metal species, this feature readily distinguishes cuprite from all the other divalent samples. Second most distinct is the spectrum of tenorite $(\mathrm{CuO})$. Although in tenorite the $\mathrm{Cu}$ is of valence +II and the $\mathrm{Cu}$ K-edge shifts to a higher binding energy with increasing oxidation state, the structure (and thus the spectrum) is dominated by the proximity to oxygen and other copper atoms around a copper center. The other spectra in Fig. 4a exhibit some differences in the shape of the absorption edge and the intensity of the white line (a XANES spectrum of Egyptian blue was clearly different and was not included). In the structures of the XAS oscillations for $E>9010 \mathrm{eV}$ (see Fig. 4b), the spectral variations are not particularly pronounced, and especially across large numbers of spectra visually and objectively discerning slight differences is difficult.

Principal components analysis was applied to the reference materials spectra (Fig. 4b). The first three principal components captured a total of $86 \%$ of the variance (PC1: $59 \%$; PC2: 17\%; PC3: 10\%). Corresponding loadings plots of the first three PCs are shown in Fig. 5, indicating the greatest variability of the spectra compared by PCA to occur in the region $9010 \mathrm{eV}-9030 \mathrm{eV}$ (first maxima and minima of the loadings plots). The loadings plots also indicate pronounced variability in the region up to $9060 \mathrm{eV}$. Both observations are consistent with the data presented in Fig. 4b. Some variance was still captured at the end of the energy range due to XAS structures typically extending to one thousand or more $\mathrm{eV}$ above the absorption edge. However, the fact that the loadings plots do not exhibit strong signals at the end of the energy range indicates that the background subtraction and normalization steps taken during data treatment were self-consistent without introducing artifacts into the PCA process. In Fig. 5 it can also be seen that there are only a few distinct features in the loadings plots, showing that the spectral differences responsible for the structure in the X-loadings plot are frequently subtle, as exhibited in Fig. 4, making definitive peak deconvolution and visual interpretation very challenging. Hence, spectral differences and relationships are better represented through the spatial ordination achieved using PCA.

Fig. 6 shows a scores plot of PC1 against PC2 for the reference spectra from Fig. $4 \mathrm{~b}$ (see also Table 1). The individual spectra are represented by numbered diamonds with the numbers explained in the legend. In the top left corner of the scores plot, an estimated uncertainty for the scores is shown as an ellipse. For clarity of presentation, these ellipses are not drawn around each data point in the plot. The error estimate was performed based on potential uncertainties associated with the input data for the PCA routine: (1)

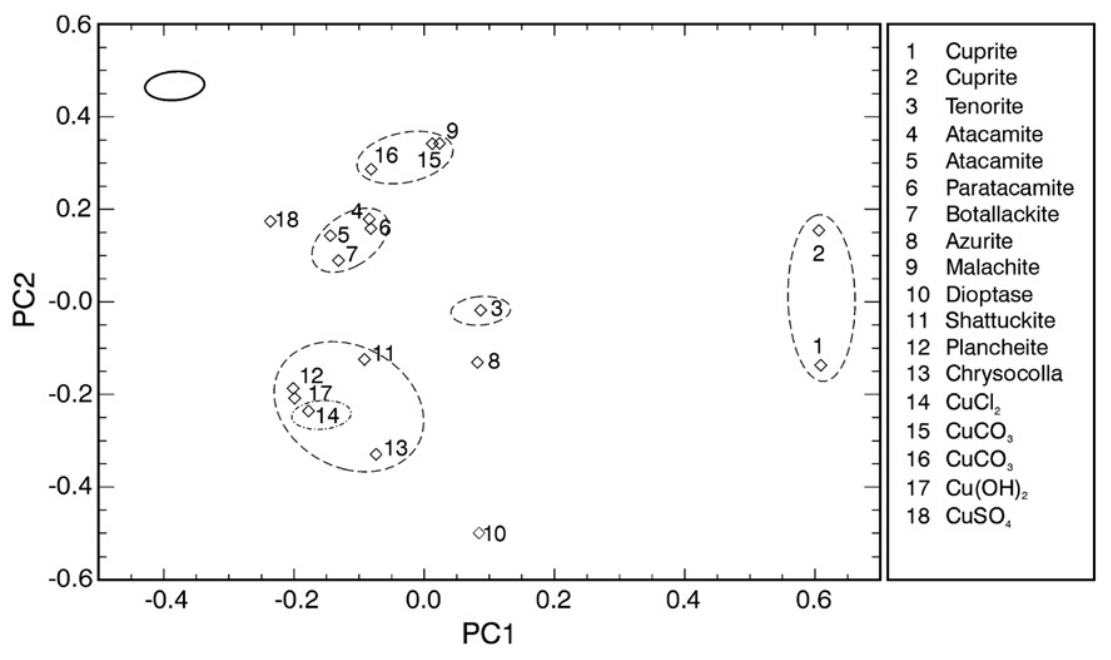

Fig. 6. PCA scores plot (PC1 vs. PC2) of minerals and laboratory chemicals. The ellipse in the top left corner represents the experimental uncertainty associated to the individual scores entries. 
mis-calibration of the energy axis of a scan, and (2) error in background subtraction through a wrongly shaped background. To estimate the first source of error, the spectrum of $\mathrm{CuSO}_{4}$ was randomly chosen, cloned twice (one with shift $+0.3 \mathrm{eV}$, one with shift $-0.3 \mathrm{eV}$ ), and added to the PCA input matrix. The second source of error was simulated by adding two spectra of $\mathrm{CuSO}_{4}$ with varying backgrounds and a total variation of $5 \%$ at the end of the energy range. The simulated uncertainties on the energy axis resulted in the short axis of the error ellipse included in Fig. 6.

As can be seen in the PCA plot, both cuprite samples are clearly separated from the other minerals in the plot, as is expected from the copper coordination chemistry/geometry differences and corresponding observable differences in the XANES spectra (Fig. 4a). It is interesting to note that the PCA resulted in a distinct separation of the cuprite data points although the edge region of the spectra (Fig. 4a) was not included in the analysis. Inspection of the spectral data presented in Fig. $4 \mathrm{~b}$ reveals that above the absorption edge cuprite results in visibly different data compared to the other spectra. Hence, as a first verification step, PCA is suitable to discern spectra related to distinctly different valence states $(\mathrm{Cu}(\mathrm{I})$ and $\mathrm{Cu}(\mathrm{II}))$.

The data point for tenorite is also well separated from the other points except the one for azurite. Further inspection including the third principal component PC3 (that is, analysis in 3D) showed that the data points for tenorite and azurite are separated well along PC3 with the uncertainty in the direction of PC3 being similar to the uncertainty along PC2 (short axis of the error ellipse). Thus, the spectra of tenorite and azurite are only partly associated, which is consistent with the data presented in Fig. 4b.

Similar assessment of the remaining PCA data results in three distinct groups coinciding with the chemical environment around the $\mathrm{Cu}$ atom (groups highlighted by dashed ellipses). The first group consists of the samples of atacamite (1 and 2), botallackite and paratacamite. These three mineral types all contain chloride and hydroxide anions co-ordinated around the $\mathrm{Cu}$ cation. The second group contains malachite and both $\mathrm{CuCO}_{3}$ references. These three materials comprise $\mathrm{Cu}$ cations complexed with carbonate anions. The third group comprises shattuckite, chrysocolla, plancheite, and $\mathrm{Cu}(\mathrm{OH})_{2}$ which represent $\mathrm{Cu}$ coordinated by silicon and/or hydroxide anions. The data point for $\mathrm{CuSO}_{4}$ is found to be separated from the other data points, although it is located relatively close to the group containing of hydroxy-chlorides. The points for dioptase (an hydroxysilicate) and $\mathrm{CuCl}_{2}$ were well separated from all groups, whereas in the case of $\mathrm{CuCl}_{2}$, this separation became visible by considering the three- dimensional scores plot including PC3, as indicated by the dashdotted ellipse in the scores plot in Fig. 6.

The PCA process has shown that certain structural environments in Cu minerals and chemicals lead to well separated groups in the scores plots:

- $\mathrm{Cu}$ (I) oxides

- $\mathrm{Cu}$ (II) oxide

- Cu-hydroxy-chlorides

- Cu-carbonates

- Cu-hydroxy-silicates and Cu-hydroxide.

The spread of reference samples here indicates the degree of natural spread encountered in those materials (coming from naturally variable sources), while the spread of multiple samples from the same source indicates the degree of variance within a sample type. The identification of groups within the dataset employed a heuristic approach informed by an a priori knowledge of the training set mineralogy. Within this classification, some groups are better defined than others. While the Cu-hydroxy-silicates show a fairly large spread, the group of Cu-hydroxy-chlorides forms a tight cluster. This means that in principle the PCA scores plot can be used to assess the chemistry of the unknown $\mathrm{Cu}$ containing green pigments.

\subsection{Assessment of unknown pigment spectra}

The PCA was repeated with the inclusion of the spectra of the green pigments (see Fig. 7). For clarity of presentation, that is, enhanced separation of the scores, the spectra of $\mathrm{Cu}(\mathrm{I})$-oxide were not included in the matrix. The first three PCs captured $77 \%$ of the variance (PC1: 48\%; PC2: 18\%; PC3: 11\%), which is less than in the previous case. Including the spectra of cuprite increased the values to $81 \%$ (PC1: $61 \%$; PC2: 13\%; PC3: 8\%), showing how spectra with distinct features decrease the number of PCs required to capture variance.

Fig. 6 shows that the data points representing Cu-hydroxychlorides and Cu-carbonates form well defined clusters. These groups were found to be robust and not largely disturbed by adding or removing spectra in the PCA input matrix. The previously outlying data points of tenorite, dioptase, and azurite have also remained in their positions, and the group of Cu-hydroxy-silicates has changed only marginally.

The points corresponding to $\mathrm{CuCl}_{2}$ and the artificially aged Egyptian blue appear within the Cu-hydroxy-silicates group. As

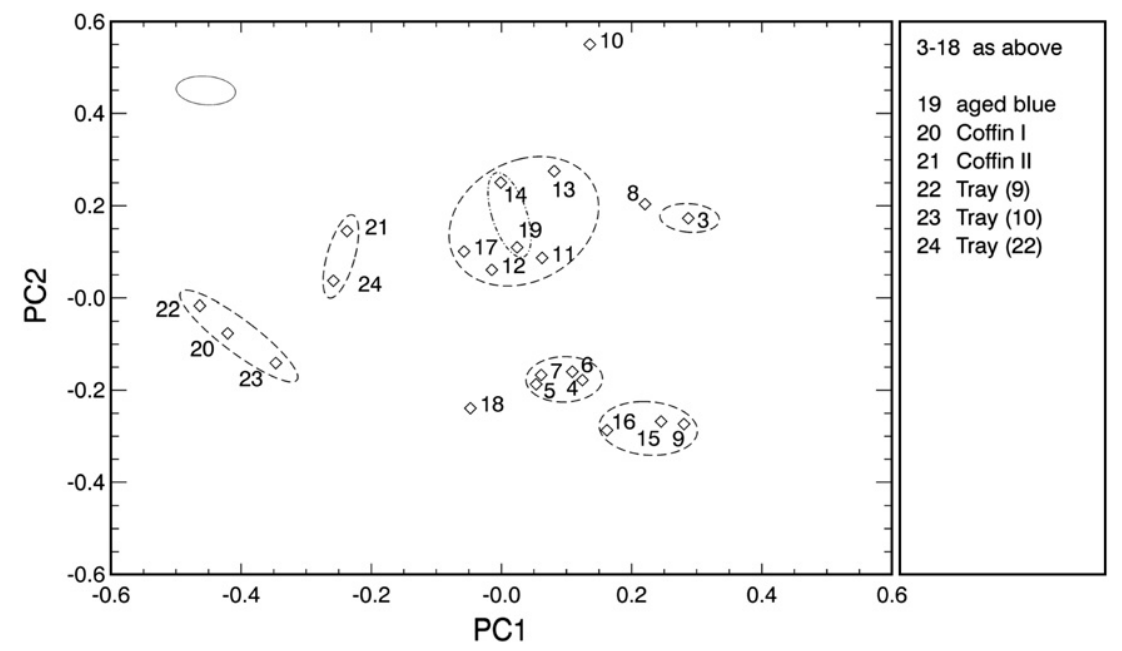

Fig. 7. PCA scores plot of PC1 vs. PC2 with cuprite 1 and 2 removed. The ellipse in the top left corner represents the experimental uncertainty associated to the individual scores entries. 
above, closer inspection, including PC3, shows that both entries are well separated from the hydroxy-silicate group along PC3. Furthermore, the two spectra form a separate group in the 3D scores plot, indicating a relationship between copper chloride and aged Egyptian blue. Using XRD, artificially aged Egyptian blue was found to contain atacamite, copper chloride hydroxide hydrate $\left(\mathrm{Cu}_{x} \mathrm{Cl}_{4}(\mathrm{OH})_{z} \cdot 2 \mathrm{H}_{2} \mathrm{O}\right)$ and eriochalcite $\left(\mathrm{CuCl}_{2}\left(\mathrm{H}_{2} \mathrm{O}\right)_{2}\right)$ as shown in Fig. 3.

The PCA scores for the coffin of Tjeseb (Coffin I) and two of the tray samples (Nos. 9 and 10) are located close to each other and are distinctly separated from all other entries in the scores plot. Furthermore, the data points for Coffin II and the third tray sample (No. 22) form another separate group. These two groups are also consistent when considering PC3.

These results agree well with the fact that Coffin I and Coffin II are different historical objects as established using traditional arthistorical research. The data also show that all pigments are not readily identified as any one of the reference materials investigated, and the spatial separation from all groups identified suggests that the green pigment cannot be described as a simple mixture of minerals. It has been suggested in the literature that green Egyptian pigments comprise malachite [17]. Given the results in Fig. 7 and the spectra in Fig. $4 \mathrm{~b}$, this cannot be confirmed for the pigments investigated here. The distinct separation of the data points of the pigments and the aged Egyptian blue also indicates that the green pigments were not a result of an ageing process that involved chlorine ions (for example, via $\mathrm{NaCl}$ precipitates). Although the spectra of the aged blue and the fragments (Fig. 4b) seem to be similar, closer inspection still reveals differences between these spectra, in particular around $9025 \mathrm{eV}$ and above $9090 \mathrm{eV}$

The grouping in Fig. 7 also shows a stronger association of tray sample No 22 with Coffin II than with Coffin I and the other tray samples. Hence, the chemistry and structure of the pigment on tray sample No 22 may be similar to that of Coffin II. This similarity suggests that the fragment from the tray belongs to an object other than Coffin I and from a period or location related to that of Coffin II. The fact that the corresponding two data points are situated closer to the scores of the reference materials (in particular the Cu-hydroxysilicate group), suggests that the Coffin II and Tray 22 pigments may contain some copper hydroxy-silicates. Further investigations will be required to clarify these points.

\section{Conclusions}

Linking PCA with XANES spectral interpretation, as has been performed here, is a valuable approach to explore data and characterize copper mineralogy in pigments that are difficult to identify using other laboratory-based micro-analytical approaches. The results have shown that the green pigments are likely not a simple combination of the reference minerals and chemicals used for comparison in this study. Also it was shown that the pigments (and thus the fragments) could be classified into two groups each containing one of the two coffin fragments. This process allowed the association of dislocated fragments (tray samples) with the coffin of Tjseb (Coffin I) either to be ruled out or verified.

The establishment of compositional groups developed through an a priori knowledge of their copper-related chemistry allowed coppercontaining pigments from Egyptian artifacts to be characterized. This work contributes to the overall growing body of knowledge of Egyptian materials and techniques used for the manufacture of funereal objects. The results obtained will also inform the treatment strategy for conservation, whereby knowledge of material composition assists decisions which remain to be made regarding storage and display in appropriate conditions, to thereby ensure its preservation and longevity.

\section{Acknowledgements}

The authors gratefully acknowledge to the valuable contributions of the Museum of Victoria for the provision of samples of mineral reference materials and Dr Edmund Welter and Dr Karen RickersAppel (HASYLAB) for support during the synchrotron beamtimes. We acknowledge financial support from the Access to Major Research Facilities Programme which is a component of the International Science Linkages Programme established under the Australian Government's innovation statement, Backing Australia's Ability.

\section{References}

[1] J. Cassar, C. Degrigny, in: A. Adriaens, J. Cassar, C. Degrigny (Eds.), Benefits of Nondestructive Analytical Techniques for Conservation, Office for the Official publications of the European Union, Luxembourg, 2005, pp. 9-12.

[2] A. Adriaens, Non-destructive analysis and testing of museum objects: an overview of 5 years of research, Spectrochim. Acta Part B 60 (2005) 1503-1516.

[3] H.G.M. Edwards, S.E. Jorge Villar, K.A. Eremin, Raman spectroscopic analysis of pigments from dynastic Egyptian funerary artefacts, J. Raman Spectrosc. 35 (2004) 786-795.

[4] J. Ambers, Raman analysis of pigments from the Egyptian Old Kingdom, J. Raman Spectrosc. 35 (2004) 768-773.

[5] K. Hühnerfuss, A. von Bohlen, D. Kurth, Characterization of pigments and colors used in ancient Egyptian boat models, Spectrochim. Acta Part B 61 (2006) 1224-1228.

[6] M.A. Denecke, Actinide speciation using X-ray absorption fine structure spectroscopy, Coord. Chem. Rev. 250 (2006) 730-754.

[7] B.M. Gordon, K.W. Jones, Synchrotron radiation and its application to chemical speciation: a review, Proceedings of the International Chemical Congress of Pacific Basin Societies, Honolulu, 1990.

[8] R.E. Shaffer, J.O. Cross, S.L. Rose-Pehrsson, W.T. Elam, Speciation of chromium in simulated soil samples using X-ray absorption spectroscopy and multivariate calibration, Anal. Chim. Acta 442 (2001) 295-304.

[9] M. Clupek, P. Matejka, K. Volka, Control charts for chemometric evaluation of Raman spectra, J. Mol. Struct. 744-747 (2005) 259-264.

[10] S. Beauchemin, D. Hesterberg, M. Beauchemin, Principal component analysis approach for modeling sulfur K-XANES spectra of humic acids, Soil Sci. Soc. Am. J. 66 (2002) 83-91.

[11] C. Jacobsen, M. Feser1, M. Lerotic, S. Vogt, J. Maser, T. Schäfer, Cluster analysis of soft X-ray spectromicroscopy data, J. Phys. IV France 104 (2003) 623-626.

[12] L. Luo, Chemometrics and its applications to X-ray spectrometry, X-Ray Spectrom. 35 (2006) 215-225.

[13] J. Riederer, in: E.W. Fitzhugh (Ed.), Artists' Pigments: A Handbook of Their History and Characteristics: Vol 3 (Artists' Pigments) (Hardcover) by Elisabeth West Fitzhugh, 3rd ed., 1997, National Gallery of Art, OUP USA.

[14] S. Pagès-Camagna, S. Colinart, C. Coupry, Fabrication processes of archaeological Egyptian blue and green pigments enlightened by Raman microscopy and scanning electron microscopy, J. Raman Spectrosc. 30 (1999) 313-317.

[15] H. Jaksch, W. Seipel, K.L. Weiner, A.E. Goresy, Egyptian blue - cuprorivaite a window to ancient Egyptian technology, Naturwissenschaften 70 (1983) 525-535.

[16] S. Pagès-Camagna, I. Reiche, C. Brouder, D. Cabaret, S. Rossano, B. Kanngießer, A. Erko, New insights into the colour origin of archaeological Egyptian blue and green by XAFS at the Cu K-edge, X-Ray Spectrom. 35 (2006) 141-145.

[17] L. Lee, S. Quirke, Ancient Egyptian Materials and Technology, Cambridge University Press, 2000.

[18] A. El Goresy, Polychromatic wall painting decorations in monuments of Pharaonic Egypt: compositions, chronology and painting technique, The Wall Paintings of Thera: Proceedings of the First International Symposium, Petros M Nomikos Conference Centre, Thera, Hellas, 1997, pp. 49-70.

[19] S. Pages-Camagna, S. Colinart, The Egyptian green pigment: its manufacturing process and links to Egyptian blue, Archaeometry 45 (2003) 637-658.

[20] P. Bianchetti, F. Talarico, M.G. Vigliano, M.F. Ali, Production and characterization of Egyptian blue and Egyptian green frit, J. Cult. Herit. 1 (2000) 179-188.

[21] D. Ullrich, Egyptian blue and green frit: characterisation, history and occurrence, synthesis, Datation-caractérisation des peintures pariétales et murales, Ravello 17 (1987) 324-332.

[22] S. Schiegl, K.L. Weiner, A.E. Goresy, Discovery of copper chloride cancer in ancient Egyptian polychromic wall paintings and faience: a developing archaeological disaster, Naturwissenschaften 76 (1989) 393-400.

[23] V. Daniels, R. Stacey, A. Middleton, The blackening of paint containing Egyptian blue, Stud. Conserv. 49 (2004) 217-230.

[24] K.V. Klementiev, XANES dactyloscope for Windows, freeware: www.desy.de/ $\sim \mathrm{klmn} /$ xanda.html, (accessed June 2008).

[25] http://cars9.uchicago.edu/ ravel/software/aboutathena.html, (accessed June 2008).

[26] B. Ravel, M. Newville, ATHENA, ARTEMIS, HEPHAESTUS: data analysis for X-ray absorption spectroscopy using IFEFFIT, J. Synchrotron Rad. 12 (2005) 537-541.

[27] IDL, Interactive Data Language, http://www.ittvis.com/index.asp (website accessed June 2008). 